\title{
Hybrid Routing Protocol with Broadcast Reply for Mobile Ad hoc Network
}

\author{
Prof. Dr. C. A. Dhote \\ Professor, Deptt. Of Comp. Sci \\ PRMIRT, Badnera.
}

\author{
Prof M.A.Pund \\ Deptt. Of CSE \\ PRMIRT, Badnera
}

\author{
Prof. R.S. Mangrulkar \\ Deptt. Of Comp. Engg \\ BDCOE, Wardha.
}

\author{
Mr. Makarand R. Shahade \\ M.E (Computer Sci. \& Engg.) \\ PRMIRT, Badnera
}

\begin{abstract}
MaNet has emerged as one of the most focused and thrust research areas in the field of wireless networks and mobile computing. In ad hoc mobile networks, routes are mainly multi hop because of the limited radio propagation range and topology changes frequently and unpredictably since each network host moves randomly. Therefore, routing is an integral part of ad hoc communications. Many routing protocols are proposed for MaNet. The protocols are mainly classified in to three categories: Proactive, Reactive and Hybrid. Proactive routing protocols attempt to maintain consistent, up-to-date routing information from each node to every other node in the network. Reactive routing protocols creates routes only when desired by the source node. Once a route has been established, it is maintained by a route maintenance procedure.

In this paper, we propose Hybrid Routing Protocol which combines the merits of proactive and reactive approach and overcome their demerits. We propose variation of this proposed Hybrid Routing Protocol (HRP), HRP-Broadcast Reply. The propose protocol creates route only when desired by the source node as in case of reactive routing protocols. The propose protocols maintain routing table at each node as in case of proactive routing protocols. Hence called hybrid routing protocol. The propose protocol takes advantage of broadcast nature of MaNet to discover route and store maximum information in the routing tables at each node. HRP-BR is compared with existing routing protocol AODV. The results shows significant reduction in routing overhead, end- to-end delay and increases packet delivery ratio over AODV.
\end{abstract}

\section{General Terms}

Routing Protocol, Manet, Proactive, Reactive, Hybrid

\section{Keywords}

Mobile ad hoc network, Hybrid Routing Protocol, AODV, Broadcast Reply (BR), etc

\section{INTRODUCTION}

MaNet [1] has emerged as one of the most focused and thrust research areas in the field of wireless networks and mobile computing. Mobile ad hoc networks consist of hosts communicating one another with portable radios. These networks can be deployed impromptu without any wired base station or infrastructure support. In ad hoc mobile networks, routes are mainly multi hop because of the limited radio propagation range and topology changes frequently and unpredictably since each network host moves randomly. Therefore, routing is an integral part of ad hoc communications, and has received interests from many researchers. Many routing protocols are proposed for MaNet. The protocols are mainly classified into three types, Proactive, Reactive and Hybrid [2,4]. In Proactive [2, 5] i.e.

Table-driven routing protocols attempt to maintain consistent, up-to-date routing information from each node to every other node in the network. These protocols require each node to maintain one or more tables to store routing information, and they respond to changes in network topology by propagating hello messages throughout the network in order to maintain a consistent network view.

Reactive routing protocol $[6,8]$ creates routes only when desired by the source node. When a node requires a route to a destination, it initiates a route discovery process within the network. This process is completed once a route is found or all possible route permutations have been examined. Once a route has been established, it is maintained by a route maintenance procedure until either the destination becomes inaccessible along every path from the source or until the route is no longer desired. The Ad hoc On-demand Distance Vector (AODV) [6, 8, 9] protocol, one of the reactive routing protocol that has receive the most attention, however, does not utilize multiple paths. In AODV [2, 6], at Every instance, route discovery is done for fresh communication which consumes more bandwidth and causes more routing overhead. The data packets will be lost during path break which occurs due to node mobility. When the network traffic requires real time delivery (voice, for instance), dropping data packets at the intermediate nodes can be costly. Likewise, if the session is a best effort, TCP connection, packet drops may lead to slow start, timeout, and throughput degradation.

This paper propose Hybrid Routing Protocol which combines the features of proactive and reactive routing protocol approaches [2]. This paper propose Hybrid Routing Protocol (HRP), HRP-BR The propose protocol creates route only when desired by the source node as in case of reactive routing protocols.

The propose protocols maintain routing table at each node as in case of proactive routing protocols. Hence called hybrid routing protocol. The proposed protocol takes advantage of broadcast nature of MaNet which is used to gain maximum routing information at the nodes in the network. HRP-BR with AODV, a highly used reactive routing protocol in Ad hoc 
network. The Results shows significant reduction in routing overhead, End-To-End delay as well as increase packet delivery ratio.

\section{PROACTIVE ROUTING PROTOCOLS}

In Proactive $[3,5,19]$ i.e. Table-driven routing protocols attempt to maintain consistent, up-to-date routing information from each node to every other node in the network. These protocols require each node to maintain one or more tables to store routing information, and they respond to changes in network topology by propagating hello messages [20] throughout the network in order to maintain a consistent network view.

\subsection{Destination-Sequenced-Distance-Vector Routing} Destination- Sequenced-Distance-Vector Routing [5] is the table driven routing based on classical Bellman-ford routing mechanism. Every mobile node in the network maintains routing table in which all of the possible destinations within the network and the number of hops to each destination are recorded. Each entry is marked with the sequence number assigned by the destination node which is used to avoid formation of routing loops. Routing table updates are periodically transmitted in order to maintain consistency. The main disadvantage is that the DSDV protocol suffers from excessive control overhead that is proportional to the number of nodes in the network and therefore is not scalable in ad hoc wireless network. Another disadvantage is that the node has to wait for a table update message initiated by the same destination node, in order to obtain information about a particular node.

\subsection{Cluster Head Gateway Switch Routing}

Cluster head gateway switch routing [21] uses hierarchical network topology. The nodes are organized into small clusters. Each cluster is having cluster-head which coordinate the communication among members of each cluster head. Clusterhead also handles issues like channel access ,bandwidth allocation in the network. The main advantage of this protocol is the better bandwidth utilization. The disadvantage of this routing protocol is that frequent cluster head changes can adversely affect routing. This also degrades the performance as the system is busy in cluster head selection rather than data transmission. Another disadvantage is the power consumption, which occurs more at the cluster-head as compared to other nodes.

\subsection{Wireless Routing Protocol}

Wireless Routing Protocol is one of the table driven routing protocol [22]. Each node is responsible for maintaining four tables i.e. Distance table(DT), Routing table(RT), Link cost table(LCT) and Message Transmission List table(MRL). The DT contains network view of the neighbors of a node. RT contains the up-to-date view of the network for all known destinations. The LCT contains the cost of relaying each message through each link. The MRL contains an entry for every update message that is to be retransmitted and maintains a counter for each entry. WRP belongs to class of path finding algorithm. WRP has same advantages as that of DSDV. In addition, it has faster convergence and involves fewer tables updates. But as it involves maintaining and processing various tables, it requires larger memory and more processing power at each node.
The comparison of proactive routing protocol [19] is summarized in Table 2.1.

Table 2.1: Comparison of Proactive Routing Protocol

\begin{tabular}{|c|c|c|c|}
\hline Parameter & DSDV & CGSR & WRP \\
\hline $\begin{array}{l}\text { Time Complexity } \\
\text { (Link } \\
\text { Addition/Failure) }\end{array}$ & $\mathrm{O}(\mathrm{d})$ & $\mathrm{O}(\mathrm{d})$ & $\mathrm{O}(\mathrm{h})$ \\
\hline $\begin{array}{l}\text { Communication } \\
\text { complexity } \\
\text { (Link } \\
\text { Addition/Failure) }\end{array}$ & $\mathrm{O}(\mathrm{x}=\mathrm{N})$ & $\mathrm{O}(\mathrm{x}=\mathrm{N})$ & $\mathrm{O}(\mathrm{x}=\mathrm{N})$ \\
\hline Routing Philosophy & Flat & Hierarchical & Flat \\
\hline Loop Free & Yes & Yes & $\begin{array}{l}\text { Yes but not } \\
\text { instantaneou } \\
\mathrm{s}\end{array}$ \\
\hline $\begin{array}{l}\text { Multicast } \\
\text { Capability }\end{array}$ & No & No & No \\
\hline $\begin{array}{l}\text { Number of } \\
\text { Required Tables }\end{array}$ & Two & Two & Four \\
\hline $\begin{array}{ll}\text { Frequency } & \text { of } \\
\text { Update } & \\
\text { Transmission } & \\
\end{array}$ & $\begin{array}{l}\text { Periodically } \\
\& \text { as Needed }\end{array}$ & Periodically & $\begin{array}{l}\text { Periodically } \\
\& \text { as Needed }\end{array}$ \\
\hline $\begin{array}{l}\text { Updates } \\
\text { Transmission to }\end{array}$ & Neighbor & $\begin{array}{l}\text { Neighbor } \\
\text { and Cluster } \\
\text { Head }\end{array}$ & Neighbor \\
\hline $\begin{array}{l}\text { Utilizes Sequence } \\
\text { Numbers }\end{array}$ & Yes & Yes & $\begin{array}{l}\text { Yes but not } \\
\text { instantaneou } \\
\mathrm{s}\end{array}$ \\
\hline $\begin{array}{ll}\text { Utilizes } & \text { "Hello" } \\
\text { messages } & \end{array}$ & Yes & No & $\begin{array}{l}\text { Yes but not } \\
\text { instantaneou } \\
\mathrm{s}\end{array}$ \\
\hline Routing Metric & $\begin{array}{l}\text { Shortest } \\
\text { Path }\end{array}$ & $\begin{array}{l}\text { Shortest } \\
\text { Path }\end{array}$ & $\begin{array}{l}\text { Shortest } \\
\text { Path }\end{array}$ \\
\hline
\end{tabular}

Abbreviations:

$\mathrm{N}=$ No. of nodes in the network $\mathrm{h}=$ Height of Routing Tree $\mathrm{d}=$ Network Diameter $\mathrm{x}=$ No. of nodes affected by topological change

\section{REACTIVE ROUTING PROTOCOLS}

Another approach used for routing is reactive approach [6,7]. This type of routing creates routes only when desired by the source node. When a node requires a route to a destination, it initiates a route discovery process within the network. This process is completed once a route is found or all possible route permutations have been examined. Once a route has been established, it is maintained by a route maintenance procedure until either the destination becomes inaccessible along every path from the source or until the route is no longer desired.

\subsection{Ad hoc On-Demand Distance Vector (AODV)}

The Ad hoc On-demand Distance Vector (AODV) [6, 8, 9] protocol, one of the on-demand routing algorithms that has receive the most attention, however, does not utilize multiple paths. It joins the mechanisms of DSDV and DSR. The periodic beacons, hop-by-hop routing and the sequence numbers of DSDV and the pure on-demand mechanism of Route Discovery and Route Maintenance of DSR are combined. In AODV [6], at Every 
instance, route discovery is done for fresh communication which consumes more bandwidth and causes more routing over-head. The source prepares RREQ packet which is broadcast to it's neighboring nodes. If neighboring node will keep backward path towards source. As soon as destination receives the RREQ packet, it sends RREP packet on received path.

This RREP packet is unicast to the next node on RREP path. The intermediate node on receiving the RREP packet make reversal of path set by the RREQ packet. As soon as RREP packet is received by the source, it starts data transmission on the forward path set by RREP packet. Sometimes while data transmission is going on, if path break occurs due to mobility of node out of coverage area of nodes on the active path, data packets will be lost. When the network traffic requires real time delivery (voice, for instance), dropping data packets at the intermediate nodes can be costly. Likewise, if the session is a best effort, TCP connection, packet drops may lead to slow start, timeout, and throughput degradation.

\subsection{Dynamic Source Routing (DSR)}

Dynamic Source Routing, DSR [2,14,16], is a reactive routing protocol that uses source routing to send packets. It is reactive protocol like AODV which means that it only requests a route when it needs one and does not require that the nodes maintain routes to destinations that are not communicating. It uses source routing which means that the source must know the complete hop sequence to the destination. Each node maintains a route cache, where all routes it knows are stored. The route discovery process is initiated only if the desired route cannot be found in the route cache. to limit the number of route requests propagated, a node processes the route request message only if it has not already received the message and its address is not present in the route record of the message. As mentioned before, DSR [9] uses source routing, i.e. the source determines the complete sequence of hops that each packet should traverse. This requires that the sequence of hops is included in each packet header. A negative consequence of this is the routing overhead every packet has to carry. However, one big advantage is that intermediate nodes can learn routes from the source routes in the packets they receive. Since finding a route is generally a costly operation in terms of time, bandwidth and energy, this is a strong argument for using source routing. Another advantage of source routing is that it avoids the need for up to-date routing information in the intermediate nodes through which the packets are forwarded since all necessary routing information is included in the packets. Finally, it avoids routing loops easily because the complete route is determined by a single node instead of making the decision hop-by-hop.

The comparison of reactive routing protocol [19] is given in Table 3.1.

Table 3.1: Comparison of Reactive Routing Protocol

\begin{tabular}{|l|l|l|}
\hline \multicolumn{1}{|c|}{ Parameter } & \multicolumn{1}{|c|}{ AODV } & \multicolumn{1}{c|}{ DSR } \\
\hline Routing Metric & $\begin{array}{l}\text { Freshest \& } \\
\text { Shortest Path }\end{array}$ & Shortest Path \\
\hline Route Maintained in & Route Table & Route Cache \\
\hline $\begin{array}{l}\text { Route Reconfiguration } \\
\text { Methodology }\end{array}$ & $\begin{array}{l}\text { Erase Route; } \\
\text { Notify Short }\end{array}$ & $\begin{array}{l}\text { Erase Route; } \\
\text { Notify Short }\end{array}$ \\
\hline Loop Free & Yes & Yes \\
\hline
\end{tabular}

\begin{tabular}{|l|l|l|} 
Multicast Capability & Yes & No \\
\hline Routing Philosophy & Flat & Flat \\
\hline $\begin{array}{l}\text { Communication } \\
\text { Complexity }\end{array}$ & $\mathrm{O}(2 \mathrm{~N})$ & $\mathrm{O}(2 \mathrm{~N})$ \\
\hline Time Complexity & $\mathrm{O}(2 \mathrm{~d})$ & $\mathrm{O}(2 \mathrm{~d})$ \\
\hline Beaconing Requirement & No & No \\
\hline
\end{tabular}

Abbreviations:

$\mathrm{N}=$ No. of nodes in the network $\mathrm{h}=$ Height of Routing Tree $\mathrm{d}=$ Network Diameter $\quad \mathrm{x}=$ No. of nodes affected by topological change

\section{HYBRID ROUTING PROTOCOLS}

Hybrid Routing Protocols combines the merits of proactive and reactive routing protocols by overcoming their demerits. In this section we put some light on existing hybrid routing protocol.

\subsection{Zone Routing Protocol (ZRP)}

Zone routing protocol is a hybrid routing protocol which effectively combines the best features of proactive and reactive routing protocol $[2,17]$. The key concept is to use a proactive routing scheme within a limited zone in the r-hop neighborhood of every node, and use reactive routing scheme for nodes beyond this zone. An Intra-zone routing protocol (IARP) is used in the zone where particular node employs proactive routing whereas inter-zone routing protocol (IERP) is used outside the zone. The routing zone of a given nodes is a subset of the network, within which all nodes are reachable within less than or equal to the zone radius hops. The IERP is responsible for finding paths to the nodes which are not within the routing zone. When a node $S$ wants to send data to node $D$, it checks whether node $D$ is within its zone. If yes packet is delivered directly using IARP. If not then it broadcasts (uses unicast to deliver the packet directly to border nodes) the RREQ packet to its peripherals nodes. If any peripheral nodes find $D$ in its zone, it sends RREP packet; otherwise the node re broadcasts the RREQ packet to the peripherals nodes. This procedure is repeated until node $D$ is located.

\section{HYBRID ROUTING PROTOCOL WITH BROADCAST REPLY}

In this paper, we proposed hybrid routing protocol with broadcast reply scheme (HRP-BR). The proposed protocol takes the advantages of both proactive and reactive routing protocol hence called Hybrid Routing Protocol(HRP).

Table 5.1: Structure of Routing Table

\begin{tabular}{|c|c|c|}
\hline Dest & Next hop & Hop count \\
\hline & & \\
\hline
\end{tabular}

- Dest : Source address on received packet.

- Next Hop : Next hop address on the path towards source node.

- Hop Count : Hop distance to reach to source node.

The RREP packet is broadcast by the node along the path. The nodes that are neighbor to the node and not along the path receives the RREP packet, updates their routing table and drop the packet. As a results of broadcasting RREP from destination towards source, node on the active path as well as nodes neighbor to active path node able to gather more routing information. 


\subsection{Analytic Study of HRP-BR}

We consider Figure 5.1 to explain working of protocol. The propos routing protocol, HRP-BR works in two different phases: Route Discovery and Route Maintenance.

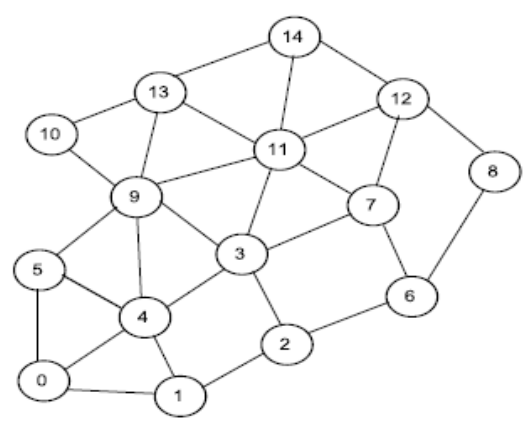

Figure 5.1: Network Topology

\subsubsection{Route Discovery in HRP-BR}

in HRP-BR, RREP packet is broadcast to all neighbors which are in the coverage area of the replying node. The RREP packet is broadcast to all neighbor nodes along with intended node. On receiving RREP packet, neighboring node makes an entry in the routing table about complete path which has received in RREP. If neighboring node is not the intended node, it drops RREP packet. If it is intended node, it adds own id in the received path and rebroadcast RREP. This process of extracting useful information from RREP packet and updates of RREP packet is carried out until RREP packet is not received by the destination which is source of RREQ packet. Figure 5.2 shows the process of RREP packet transmission.

In the Figure 5.2, node 14 is sending a RREP packet is response to RREQ from node 0 . Routing table at node 14 after processing RREQ packet from node 0 is shown in Table 5.2

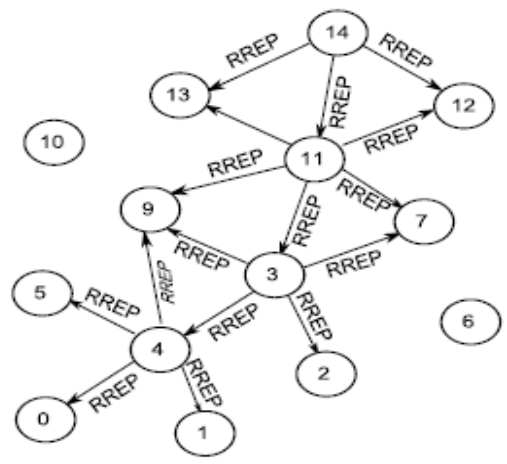

Figure 5.2: RREP Transmission in the Network

Table 5.2: Routing Table at Node 14

\begin{tabular}{|l|l|l|}
\hline Dest & Next hop & Hop count \\
\hline 0 & 11 & 4 \\
\hline
\end{tabular}

At node 14 the next hop towards node 0 is node 11 shown in Table 4.1 with node 11 as intended node. It prepares RREP packet and broadcast with node 11 as the intended node. Neighboring node $11,12,13$ will receives the RREP packet.
The nodes which are not intended node will drop the RREP packet after updating there routing table as shown in Table 5.3 and 5.4.

Table 5.3 Routing Table at Node 13

\begin{tabular}{|l|l|l|}
\hline Dest & Next hop & Hop count \\
\hline 0 & 11 & 4 \\
\hline 14 & 14 & 1 \\
\hline 11 & 11 & 1 \\
\hline 2 & 9 & 3 \\
\hline
\end{tabular}

After receiving RREQ by intended node 11 , it searches node 0 in own routing table and finds next node towards source node 0 which is node 3 called new intended node as shown in Table 5.5. It then add it's own address in the received RREP packet. So modified reply path in RREP packet is $14-11$. Then it searches node 0 in its own routing table and finds next hop towards source node 0 , which

Table 5.4: Routing Table at Node 12

\begin{tabular}{|l|l|l|}
\hline Dest & Next hop & Hop count \\
\hline 0 & 11 & 4 \\
\hline 14 & 14 & 1 \\
\hline 11 & 11 & 1 \\
\hline 2 & 7 & 2 \\
\hline
\end{tabular}

Table 5.5: Routing Table at Node 11

\begin{tabular}{|l|l|l|}
\hline Dest & Next hop & Hop count \\
\hline 0 & 3 & 3 \\
\hline 14 & 14 & 1 \\
\hline 3 & 3 & 1 \\
\hline 2 & 7 & 2 \\
\hline 9 & 9 & 1 \\
\hline
\end{tabular}

is termed as new intended node. After modification of RREP packet, intended node 11 will broadcast modified RREP packet to all its neighboring nodes i.e. node $13,14,12,7,3$ and 9. Then new intended node 3 rebroadcast modified RREP packet to all neighbors. This process is repeated until RREP packet is reached to the destination node $O$ which is source of RREQ packet. The process of RREP packet transmission is as shown in the Figure 5.2.

Consider few more CBR data traffic as follows

- CBR 1: from node 9 to node 0 starts at 4.0 and ends at 6.0.

- CBR 2: from node 1 to node 11 starts at 5.0 and ends at 7.0.

- CBR 3: from node 5 to node 14 starts at 8.0 and ends at 9.0.

- CBR 4: from node 2 to node 13 starts at 10.0 and ends at 12.0.

The routing table for some of the node for above scenario is given in Tables 5.3, 5.4, 5.8 and 5.6 and 5.5. As the number of CBR data traffic increases, more and more information are added to the routing table. Suppose node 13 want to communicate with node 2. In the routing table of node 13 as shown in Figure 5.2, 
there exist a path to node 2 . There is no need for route discovery as it usually happen in reactive protocol. Node 13 can immediately start transmitting data to node 2 .

Table 5.6: Routing Table at Node 5

\begin{tabular}{|l|l|l|}
\hline Dest & Next hop & Hop count \\
\hline 0 & 0 & 1 \\
\hline 4 & 4 & 1 \\
\hline 3 & 4 & 2 \\
\hline 11 & 4 & 3 \\
\hline 14 & 4 & 4 \\
\hline 2 & 4 & 3 \\
\hline 9 & 9 & 1 \\
\hline 13 & 9 & 2 \\
\hline
\end{tabular}

Table 5.7: Routing Table at Node 10

\begin{tabular}{|l|l|l|}
\hline Dest & Next hop & Hop count \\
\hline 0 & 13 & 5 \\
\hline 2 & 9 & 3 \\
\hline 13 & 13 & 1 \\
\hline 9 & 9 & 1 \\
\hline
\end{tabular}

Table 5.8: Routing Table at Node 8

\begin{tabular}{|l|l|l|}
\hline Dest & Next hop & Hop count \\
\hline 0 & 12 & 5 \\
\hline 2 & 7 & 2 \\
\hline
\end{tabular}

\subsubsection{Route Maintenance in HRP-UR}

Usually link failure occurs due to node mobility. A node on detecting link failure send a route error message (RERR). This RERR message is forwarded to the source. Source will start fresh route discovery procedure after receiving RERR message This process is shown in Figure 5.3.

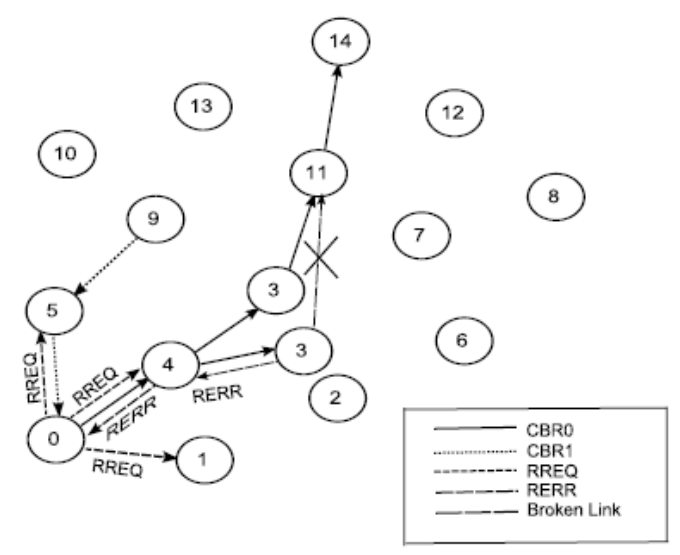

Figure 5.3: Link Failure and Recovery

\section{CONCLUSION}

The Proactive and Reactive approach for routing in ad hoc network have their merits and demerits. The Proposed routing protocol will have an advantage of both proactive and reactive approach. Backup routing in proposed scheme will helpful in path break up to some extent. Here we want to conclude by saying that the analytic study of the new hybrid approach will result in less routing overhead than most of the routing algorithm such as AODV and DSDV. The resented in this paper is related with the efficient routing issue, which is most demanding and thrust area of ad hoc network. We have a new Hybrid Routing Protocol with variation in route reply. we have a hybrid routing protocol scheme with Broadcast reply (HRP-BR).

\section{REFERENCES}

[1] Mobile Adhoc Network (MaNet). http://www.ietf.org/html.charters/manetcharter.html.

[2] C. Siva Ram Murthy and B.S. Manoj. Ad Hoc Wireless Networks Architectures and Protocol, volume ISBN:81-2970945-7. Pearson Education, first indian reprint,2005 edition, 2005.

[3] Santa Barbara Elizabeth M. Royer and Chai Keong Toh. A Review of Current Routing Protocols for Adhoc Mobile Wireless Networks. IEEE Personal Communications, pages 46-55, April 1999.

[4] Y. Zhang V. Kawadia and B. Gupta. System Services for Implementing Ad-hoc Routing: Architecture, Implementation \& Experiments. In First Inter-national Conference on Mobile System, Application and Services(Mobisys), pages 99\{114. San Francisco, CA., June 2003.

[5] C. P. P. Bhagwat. Highly Dynamic Destination Sequenced Distance Vector DSDV Routing for Mobile Computers. Proceeding of ACM SIGCOM, pages 234 - 244, September 1994. [6] E. Royer C. Perkins and S. Das. Ad hoc On-demand Distance Vector (aodv) routing. (RFC 3561), July 2003.

[7] C. K. Toh. Ad Hoc Mobile Wireless Networks-Protocols and Systems, chapter 6, pages 79-94. Prentice Hall, 2002.

[8] Cenker Demir and Cristina Comanicia. An Auction Based AODV Protocol for Mobile Ad hoc Network with Selfish Nodes. IEEE International Conference ICC'07, pages 3351-3356, June 2007.

[9] Rendong Bai and M. Singhal. DOA: DSR over AODV protocol for mobile ad hoc network. IEEE Transaction on Mobile Computing, 5:1403-1416, Oct 2006.

[10] P. K. Pattanaik and R. Mall. Challenges in ad hoc networks. Sidhanth Journal, pages 153-160, 2007.

[11] M. Woo S. Singh and C. S. Raghvendra. Power Aware Routing in Mobile Ad-Hoc Networks. In Proceedings of ACM/IEEE MOBICOM, pages 181-190. Dallas, Texas, October 1998.

[12] K. Y. Wang R. Dube, C. D. Rais and S. K. Tripathi. Signal Stability Based Adoptive Routing SSA for Ad hoc Mobile Network. IEEE Personal Communication, 4:36-45, Feb 1997.

[13] J. H. Chang and L. Tassiulas. Energy Conserving Routing in Wireless Ad hoc Network. In IEEE Conference on Computer Communications INFOCOM, pages 22-31, Tel Aviv Israel, March 2000.

[14] S. R. Das C.E. Perkins, E. M. Royer and M.K. Marina. Performance Comparison of Two On-demand Routing Protocols 
for Ad hoc Networks. IEEE Personal Communications Magazine Special Issue on Ad hoc Networking, pages

16-28, Feb 2001.

[15] David B. Johnson. Routing in Ad hoc Networks of Hmobile Hosts. IEEE Workshop on Mobile Computing Systems and Applications, pages 158-163, Dec 1994.

[16] D. B. Johnson and D. A. Maltz. Dynamic Source Routing in Ad hoc Wireless Network. In the Book, Mobile Computing, pages 153-181, 1996.

[17] E. Topalis S. Giannoulis, C. Antonopoulos and S. Koubias. Zrp Versus DSR and TORA: A Compressive Survey on ZRP Performance. 10th IEEE Conference, ETFA 2005, 1(ISBN:07803-9401-1), Sept 2005.

[18] L. Wang and S. Olariu. A Two Zone Hybrid Routing Protocol for Mobile Ad hoc Network. IEEE Transaction on Parallel and Distributed Systems, 12:1105-1116, Dec 2004.

[19] Ankur Khetrapal. Routing Techniques for Mobile Ad hoc Networks Classification and Qualitative/Quantitative Analysis. In $I C W N$, pages 251-257, 2006.
[20] Ian D. Chakeres and Elizabeth M. Belding-Royer. The Utility of Hello Messages for Determining Link Connectivity. In Fifth International Symposium on Wireless Personal Multimedia Communication WPMC, pages 504-508. Honolulu,Hawaii, October 2002.

[21] C.C. Chiang. Routing in Clustered Multihop, Mobile Wireless Networks with Fading Cchannel. In In IEEE Proceeding, Sicon'97, pages 197-211, April 1997.

[22] S. Murthy and J.J. Garcia-Luna-Aceves. An Efficient Routing Protocol for Wireless Networks. In ACM Mobile Networks and Applications, pages 183-197, October 1996. 